\title{
Emilio Willems
}

e Egon Schaden na história da Antropologia

\section{JOÄO BAPTISTA BORGES PEREIRA}

$\mathrm{N}$ a história da consolidação da Antropologia da Universidade de São Paulo, que se iniciou oficial e sistematicamente em 1941, dois professores aparecem com merecido destaque: Emilio Willems e Egon Schaden.

Emilio Willems, atualmente professor emérito da Vanderbilt Unipersity, para onde se transferiu em 1949, fez um percurso acadêmico singular. Imigrante alemão, diplomado em Economia pela Universidade de Berlim, professor secundário nos estados do Paraná e de Santa Catarina, chegou à Universidade de São Paulo apoiado em pesquisas de campo publicadas desde 1934 e levado pelas mãos de Fernando de Azevedo. Na Faculdade de Filosofia ministrou aulas de Sociologia, disciplina em que obteve seu título de livre-docência em 1937.

Sempre estimulado pelo professor Fernando de Azevedo, Willems deixa o campo da Sociologia Educacional para se dedicar à Antropologia, disciplina que desde 1936 vinha sendo ministrada em caráter intermitente na Faculdade de Filosofia. Sob sua orientação, em 1941, passa a ser lecionada como matéria obrigatória nos cursos de Ciências Sociais, Geografia e História e, em 1947, consegue que seja instituído o diploma de especialização em Antropologia, juntamente com os de Sociologia e Ciência Política. Um ano depois, em 1948, de disciplina obrigatória a Antropologia passa à Cadeira $n^{\circ} 49$, sendo indicado para regê-la o professsor Willems.

Paralelamente à intensa atuação política visando a novos arranjos estruturais que conduziriam à ampliação institucional da área de conhecimento a qual se dedicara, Willems desenvolvia expressivo trabalho de ensino e de pesquisa de campo, formando alunos e discípulos que posteriormente continuariam a sua obra. Se no ensino dava grande atenção à Antropologia Física ou Biológica, como exigência curricular, nos domínios da pesquisa, sob a influência teórica da Antropologia americana, realizou estudos pioneiros e marcantes que se tornaram verdadeiros clás- 
sicos da literatura antropológica brasileira. A Willems devem-se pesquisas de campo e reflexóes que tiraram a Antropologia feita no país de seu interesse apenas pelo biológico e pelo tribal e a colocaram como ciência preocupada com a análise e a interpretação de aspectos cruciais da sociedade complexa brasileira. Assim, inspirando-se em Robert Redfield, um atípico e sofisticado neo-evolucionista norte-americano, realizou o seu primeiro estudo de comunidade no Brasil, tendo como um de seus assistentes de pesquisa o aluno Florestan Fernandes (Uma vila brasileira - tradição e mudança. São Paulo, Difusão Européia do Livro, 1961).

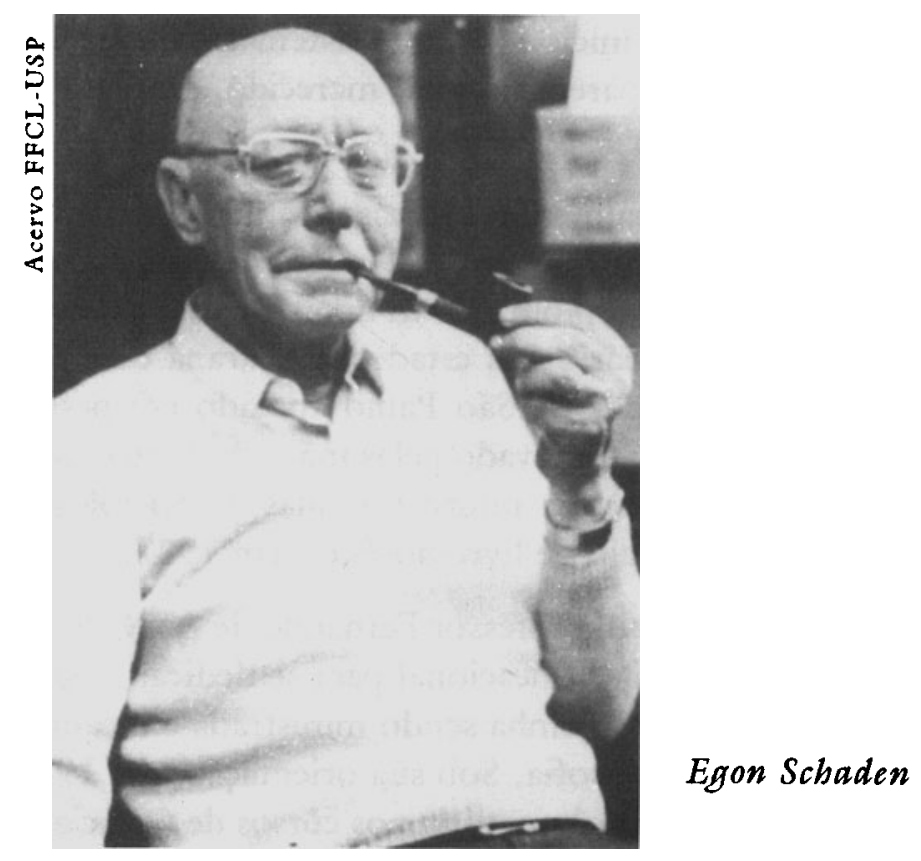

Em outra pesquisa de campo levada a cabo nas partes meridionais do país, Willems, pela primeira vez entre nós, realizou um estudo de fôlego a respeito de um tema que o interessara desde a sua chegada ao Brasil: a imigração alemã (Aculturação dos alemães no Brasil. São Paulo, Editora Nacional, 1946). Nesse estudo, joga com três vertentes temáticas - etnia, vida rural e comunidade - dentro do esquema de vanguarda teórica da época - a aculturação.

Além de uma série expressiva de pesquisas e estudos sobre a vida nacional, na qual o étnico, o rural e o interiorano estavam quase sempre presentes, Willems elaborou dois dicionários que durante décadas serviram de guia para estudiosos em Sociologia e Antropologia. O pri- 
meiro, feito de parceria com Herbert Baldus (Dicionário de etnologia e sociologia. São Paulo, Editora Nacional, 1939) e, o segundo, assinado apenas por ele (Dicionário de sociologia. Porto Alegre, Globo, 1950).

Após a sua transmigrafão para os Estados Unidos, Emilio Willems retornou ao Brasil inúmeras vezes. Na última, no final da década de 50, esteve no país realizando etapa de uma pesquisa sobre a influência do protestantismo na América Latina. Nesse período, ministrou curso de pós-graduaçáo na Escola Pós-Graduada da Fundaçáo Escola de Sociologia e Política, retomando assim contato com uma insti-

Emilio Willens

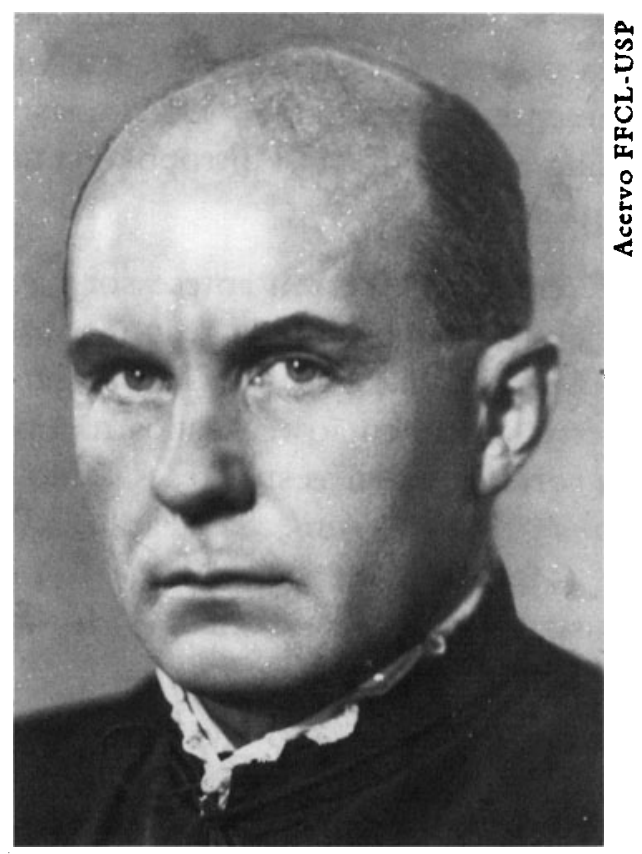

tuição com a qual manteve laços muito íntimos em anos anteriores. Foi co-fundador e diretor da revista Sociologia, periódico que durante quase três décadas teve papel de relevo na sistematização e circulação do pensamento sociológico e antropológico brasileiro.

Egon Schaden, primeiro assistente de Willems, assume a regência da Cadeira n 49, em 1950. Neto de alemães de Santa Catarina, diplomado em Filosofia na própria USP, onde teve Lévi-Strauss como um de seus professores, Schaden desenvolveu toda a sua carreira acadêmica na Faculdade de Filosofia, obtendo os títulos de doutor, livre-docente e catedrático. Se com o professor Willems a Antropologia passara de mera disciplina intermitente à cadeira, com o professor Schaden iria se am- 
pliar e se fortalecer institucionalmente. Desde 1935, paralelamente à disciplina antropológica, funcionava na Faculdade de Filosofia a cadeira de Etnografia do Brasil e Lingua Tupi-Guarani, sob a regência do professor Plínio Ayrosa. Era uma dualidade institucional que cortava, por assim dizer, um campo intelectual e impedia a Antropologia de assumir a sua integralidade como área de saber, tanto no plano do ensino, como no da pesquisa. Tal situaçăo mantinha-se graças ao prestígio pessoal e poder político do professor Ayrosa. Com a morte desse catedrático, em 1963, Schaden consegue eliminar essa dualidade, vencendo a resistência da área da Sociologia, liderada por Florestan Fernandes, que pretendia trazer Herbert Baldus, do Museu Paulista, para reger a cadeira de Etnografia. Cria-se, entăo, a cadeira de Línguas Indígenas do Brasil, que passa para o Setor de Letras, e a cadeira de Antropologia incorpora definitivamente as disciplinas de Etnologia e Etnografia brasileiras, dando ao ensino e à pesquisa da Antropologia na USP o perfil fundamental que ostenta até hoje.

Diferentemente de seu antecessor na cátedra, Schaden dedica-se preferencialmente ao estudo de grupos tribais. Com ele, a Etnologia ou a Antropologia dos indígenas brasileiros ganha grau de sofisticação teórica que estudos até então realizados náo possuíam. Suas três grandes pesquisas correspondem às suas teses de doutorado ( $A$ mitologia berdica de tribos indigenas do Brasil. São Paulo, EDUSP, 1989, 3ª ed.), livredocência (Aspectos fundamentais da cultura guarani. São Paulo, EPU/Edusp, 1974, 3 ed.) e cátedra (Aculturafáo indigerra. Sáo Paulo, Pioneira, 1969).

Mitologia Herodica, incluída posteriormente pela Congregaçáo da Faculdade de Filosofia entre as vinte melhores teses a serem editadas ou reeditadas pela Universidade, foi saudada como uma grande contribuiçáo à etnologia do país. Herbert Baldus, um dos mais severos críticos de Schaden, considerou-a uma das mais importantes obras da Etnologia brasileira. Uma mina de dados magistralmente coordenados e um manancial de interessantes sugestóes (Bibliografia crttica da etrologia brasileira, São Paulo, 4ํ Centenário, 1951:631).

Embora seja um estudo confessadamente reducionista ou eclético do ponto de vista teórico-metodológico, nota-se a grande influência da ótica funcionalista que vai melhor se delineando em trabalhos posteriores de Schaden.

Em Aspectos fundamentais da cultura guarani ele revela a sua preferência pelos esquemas teórico-configuracionista, funcionalista e, principalmente, pela então prestigiosa teoria da aculturaçáo. Teoricamente, nesse estudo, Schaden é um autor do seu tempo. 
Finalmente, em Aculturafío indigena, Schaden faz, ao lado de um balanço crítico dos principais estudos de aculturação realizados pela Etnologia brasileira, uma crítica (um tanto benevolente) ao alcance explicativo da teoria da aculturaçăo. Lida, hoje, essa crítica pode ser interpretada também como uma defesa dessa teoria de contactos culturais que durante quase duas décadas reinou absoluta entre nós e que começava a ser demolida, principalmente, pelo estruturalismo de LéviStrauss. É preciso reter que a polêmica estruturalismo/aculturaçáo, mediada pela aceitaçáo ou não do próprio conceito de cultura, vinha se desenvolvendo há anos, em Antropologia, entre adeptos das Escolas Inglesa e Americana.

Além de suas pesquisas de campo, Schaden encontrou tempo para realizar traduçōes de grande envergadura: através de suas impecáveis traduçóes de Karl Von den Stein, Fritz Krause e Paul Ehrenreich as novas geraçóes de antropólogos familiarizaram-se com os autores que deram, na linhagem alemã, os fundamentos da etnologia brasileira no século XIX.

No rol de suas contribuiçóes à Antropologia brasileira, na qual o índio era onipresente, a fundaçáo, em 1953, da Revista de Antropologia deve ser ressaltada. Essa revista, que circula até hoje, se propunha (e cumpriu) a acolher em suas páginas colaboraçóes de especialistas, independentemente de sua orientaçáo ideológica e de sua marca e grau de sofisticaçáo teóricas. Foi criada como um periódico sem preconceitos, aberto a todos os sérios pesquisadores, brasileiros ou não.

Em 1967 o professor Egon Schaden aposenta-se prematura e precipitadamente da Universidade de São Paulo para reger, em caráter efetivo e vitalício, a cátedra de Etnologia da Universidade de Bonn, na Alemanha, onde estivera várias vezes como professor visitante.

Questốes pessoais e familiares o impediram de assumir essa funçáo que tanto almejara e de que tanto se orgulhava. Aproveitou esse tempo pós-aposentadoria para ministrar cursos, seminários e conferências na Alemanha, França, Canadá, Suíça, Japáo, Colômbia, Equador e Paraguai, até que, de volta ao Brasil, fixa-se no quadro docente da Escola de Comunicaçōes e Artes da USP. Nessa instituiçáo passa os seus derradeiros dias acadêmicos, trabalhando na consolidação de um novo campo da Antropologia - a Antropologia da Comunicaçáo -, enquanto amargava, sem alardes, a violência que sofrera do regime militar. Os ditadores de plantão caçaram-lhe o direito de sair do país.

Joto Baptista Borges Percira é professor do Departamento de Antropologia da Faculdade de Filosofia, Letras e Ciencias Humanas da USP. 